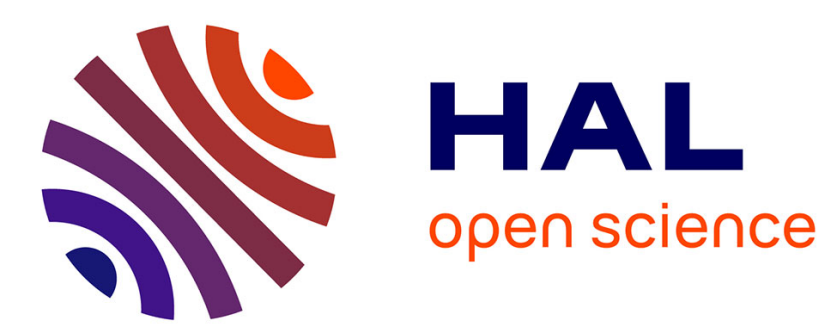

\title{
Using SPOT data for calibrating a wheat growth model under mediterranean conditions
}

\author{
Jan Clevers, Oscar Vonder, Raymond Jongschaap, Jean-François Desprats, \\ Christine King, Laurent Prévot, Nadine Bruguier
}

\section{- To cite this version:}

Jan Clevers, Oscar Vonder, Raymond Jongschaap, Jean-François Desprats, Christine King, et al.. Using SPOT data for calibrating a wheat growth model under mediterranean conditions. Agronomie, 2002, 22 (6), pp.687-694. 10.1051/agro:2002038 . hal-00885985

\section{HAL Id: hal-00885985 \\ https://hal.science/hal-00885985}

Submitted on 1 Jan 2002

HAL is a multi-disciplinary open access archive for the deposit and dissemination of scientific research documents, whether they are published or not. The documents may come from teaching and research institutions in France or abroad, or from public or private research centers.
L'archive ouverte pluridisciplinaire $\mathbf{H A L}$, est destinée au dépôt et à la diffusion de documents scientifiques de niveau recherche, publiés ou non, émanant des établissements d'enseignement et de recherche français ou étrangers, des laboratoires publics ou privés. 


\title{
Using SPOT data for calibrating a wheat growth model under mediterranean conditions
}

\author{
Jan G.P.W. CleVERS ${ }^{a *}$, Oscar W. VONDER ${ }^{\mathrm{a}}$, Raymond E.E. JONGSCHAAP ${ }^{\mathrm{b}}$, Jean-François DeSPRATS ${ }^{\mathrm{c}}$, \\ Christine $\mathrm{KING}^{\mathrm{c}}$, Laurent PRÉVOT ${ }^{\mathrm{d}}$, Nadine BRUGUIER ${ }^{\mathrm{d}}$

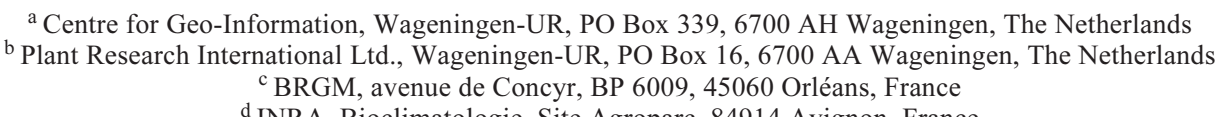

(Received 15 April 2002; accepted 21 May 2002)

\begin{abstract}
This paper describes the use of SPOT satellite data for deriving crop biophysical parameters at various dates during the growing season. In particular, the leaf area index (LAI) was estimated by using the semi-empirical CLAIR model. Subsequently, these LAI estimates were used for calibrating the mechanistic crop growth model ROTASK. This study is based on measurements obtained during the Alpilles experiment in Southern France from October 1996 to November 1997. Thus far, this methodology was applied using ground-based and airborne optical remote sensing data. In this study, it was shown that the methodology could also be applied using spaceborne imagery. Moreover, it was shown that parameters describing the relationship between the weighted difference vegetation index and the LAI for cereals in the Netherlands could also be applied to wheat crops in Southern France. This shows that this approach may have a broad applicability and that parameter estimates are not site-specific.
\end{abstract}

growth model / wheat / calibration / remote sensing / SPOT

Résumé - Utilisation des données SPOT pour caler un modèle de croissance du blé en climat méditerranéen. Ce papier décrit l'utilisation des données de SPOT pour obtenir des paramètres biophysiques de la cultures à différentes dates durant la saison de végétation. En particulier, l'indice foliaire (LAI) a été estimé en utilisant le modèle semi-empirique CLAIR. Ces estimations de LAI ont été utilisées par la suite pour caler le modèle de croissance mécaniste ROTASK. Cette étude s'appuie sur les mesures obtenues durant l'expérience Alpilles dans le sud de la France d'octobre 1996 à novembre 1997. Jusque-là cette méthodologie était appliquée en utilisant des mesures au sol et de télédétection optique aéroportée. Dans cette étude, il a été montré que la méthode pourrait aussi être appliquée en utilisant des images spatiales. De plus, il a été montré que les paramètres décrivant la relation entre l'indice de végétation pondéré et l'indice foliaire pour les céréales aux Pays-Bas pourraient aussi être appliqués aux cultures de blé dans le sud de la France. Cela montre que cette approche pourrait être applicable dans un large domaine et que les estimations des paramètres ne sont pas spécifiques.

modèle de croissance / blé / calage / télédétection / SPOT

\section{INTRODUCTION}

Monitoring agricultural crops during the whole growing season is important for observing the growth and development of the crop. This can provide significant information in order to be able to adjust the growth of the crops, e.g. for applications in the field of precision farming. So-called site-specific management can optimize the input of, for instance, nutrients and pesticides according to the need of the plants. In this way it can minimize negative effects on the environment. Secondly, it can provide information for obtaining yield predictions well before harvest time, which is of importance for decision making at various levels, for logistics and for trade activities. More and more use is being made of crop growth models for such monitoring activities. A serious drawback of crop growth models is the absence of an

Communicated by Frédéric Baret (Avignon, France)

* Correspondence and reprints

jan.clevers@staff.girs.wag-ur.nl 
accurate spatial component. If a spatial component is included, the spatial information generally is only available at a very aggregated level. Examples are meteorological and soil-related information. Remote sensing data provide information on the crop growth as a result of spatially heterogeneous soil and management factors. As a result, remote sensing data can be used for calibrating crop growth models for actual field conditions, thus rendering the combination of growth models and remote sensing data a valuable tool for growth monitoring $[3,9,10,13]$.

Mechanistic and dynamic crop growth models describe the relationship between plant physiological processes and environmental factors such as solar irradiation, temperature, and water and nutrient availability. They simulate the daily growth and development of crops, and finally a simulation of yield at harvest time is obtained. The effect of management practices (like nitrogen fertilization) on final yield can be simulated, indicating whether this is advisable and financially profitable or not. These models may also be used for yield prediction early in the growing season by assuming average meteorological conditions. However, if possible, modeling should be guided by some sort of information on the actual status of the crop throughout the growing season. Optical remote sensing can provide such information for calibrating a growth model at the level of individual fields $[3,5]$.

A key variable used for calibrating a crop growth model is the leaf area index (LAI). The LAI may be obtained from optical remote sensing data by analytically inverting a radiative transfer model. However, good results are already obtained by using a semi-empirical approach (using a vegetation index) for estimating the LAI regularly during the growing season [9]. Thus far, most studies applying such a multitemporal approach have used ground-based or airborne remote sensing data. In this paper we will focus on winter wheat using spaceborne information. Bouman et al. [4] derived relationships for winter wheat amongst other crops using ground-based reflectance measurements in the Netherlands. These relationships were verified using airborne measurements in the Netherlands [7]. One possibility for calibrating a crop growth model is to "force" the model simulation through obtained LAI estimates by resetting the simulated LAI value to the retrieved LAI value at a remote sensing event and then continue the day-to-day simulation until the next remote sensing event. Another possibility is to "force" daily-interpolated LAI values retrieved by remote sensing. For the latter approach, enough measurements throughout the growing season are required to construct a reasonable LAI curve.

This paper will focus on the following research topics:

- Application of a semi-empirical approach for estimating the LAI, developed for ground-based measurements, to high resolution optical satellite data at different moments during the growing season. Results are compared with field measurements.

- Assimilation of the LAI estimates into a calibrated crop growth model. The simulated LAIs and grain yields during the growth period are compared with field measurements.
This should indicate whether remote sensing has additional value for a well-calibrated growth model.

- Application of the methods and relationships valid for the Netherlands to winter wheat grown under semi-arid conditions in the South of France.

\section{METHODOLOGY}

First, a simple reflectance model (CLAIR) was used for estimating the LAI from optical remote sensing data. Subsequently, these LAI values were "forced" on a calibrated crop growth simulation model in two ways:

(1) a reset of the simulated LAI values by the LAI values retrieved from the SPOT images (called "reset" hereafter), and

(2) "forcing" the interpolated SPOT LAI values continuously on the simulation model (called "interpolation" hereafter).

\subsection{Estimating leaf area index}

As stated before, estimation of the LAI of agricultural crops during the growing season can be based on vegetation indices. Clevers $[5,6]$ derived a simplified, semi-empirical reflectance model for estimating LAI (the CLAIR model). In this model, first, the WDVI (weighted difference vegetation index) is ascertained as a weighted difference between measured near-infrared (NIR) and red reflectances, assuming that the ratio of NIR and red reflectances of bare soil is constant. In this way, a correction for the influence of soil background is performed:

$$
\mathrm{WDVI}=\mathrm{NIR}-(\mathrm{C} \times \mathrm{Red})
$$

$\mathrm{NIR}=$ measured NIR reflectance;

Red $=$ measured red reflectance;

$\mathrm{C}=$ slope of the (soil-specific) soil line, or ratio between NIR and red reflectance of soil.

Subsequently, this WDVI is used for estimating LAI according to the inverse of an exponential function:

$$
\mathrm{LAI}=-1 / \alpha \times \ln \left(1-\mathrm{WDVI} / \mathrm{WDVI}_{\infty}\right),
$$

with $\alpha$ and $\mathrm{WDVI}_{\infty}$ as two empirical parameters.

The CLAIR model was evaluated for various crops $[4,7]$. Ground-based reflectance measurements obtained in the Netherlands over different experimental fields for more than 10 years were used. For instance, a single regression line was found that was not significantly different for cereals such as wheat, barley and oats during the vegetative growth period (before heading). Such ground-based parameter estimates could be applied to airborne measurements [8].

However, for the barley crop at the reproductive stage the regression line was significantly different from the one at the vegetative stage $[1,4,7]$. At the vegetative stage, for $\alpha$ a value of 0.252 was obtained and for $\mathrm{WDVI}_{\infty}$ a value of 68.6 , if the WDVI is based on NIR and red reflectance [7]. At the reproductive stage, for $\alpha$ a value of 0.530 was obtained and for 
WDVI $_{\infty}$ a value of 57.9 . For both development stages different parameter estimates are being used, because the vegetation structure is very different, with ears being present and a more erectophile leaf angle distribution at the reproductive stage.

In the current study the parameter estimates obtained for cereals in the Netherlands [7] will be applied to cereals in the South of France. Moreover, the results for ground-based and airborne data will be applied to spaceborne data.

\subsection{Calibrating the crop growth model}

The mechanistic crop growth model ROTASK 1.5 is a dynamic simulation model for the growth of a range of arable crops. It has a continuously running water and soil organic matter balance, and crop growth is driven by daily weather data [11]. Management practices such as sowing, fertilization and irrigation can be introduced. Potential, water-limited and nitrogen-limited growth rates are calculated on a daily basis and eventual growth rates are given according to the law of minimums. The model was calibrated for winter wheat and for the soil conditions of the test site near Avignon using 1996, 1997 and 1998 field data [12].

During simulation, two methods of introducing the LAI values, estimated from the SPOT images, were applied.

(1) A reset of the LAI value was performed at the date of each SPOT observation in the growing season. Such a reset means that the simulated LAI is replaced with the estimated LAI value obtained from the remote sensing information. After a reset at a SPOT observation date, the model simulated the LAI development until the next SPOT observation date, when again a reset was done.

(2) The LAI values were simulated until the date of the first SPOT observation. Then, LAI values were estimated from the SPOT data and linearly interpolated from these estimates for the dates between the SPOT observation dates. Subsequently, these LAI values were "forced" on the model, meaning that the model was "forced" to calculate light interception with these LAI values. Constrained by these LAI values, the model simulated the dry matter production and partitioning between organs. Finally, after the date of the last SPOT observation, the LAI values were simulated again until the end of the growing season.

\section{ALPILLES EXPERIMENT}

Within the framework of the EU-financed ReSeDA project, a consistent and comprehensive data set was acquired during the whole growing season of winter and summer crops from October 1996 to November 1997. It included field measurements and airborne and satellite remote sensing measurements. The Alpilles experimental site was located near Avignon (South East of France) in the Rhone valley. Its size was about $4 \mathrm{~km} \times 5 \mathrm{~km}$. It is a very flat area with fields large enough $(200 \mathrm{~m} \times 200 \mathrm{~m})$ to extract pure pixels from high spatial resolution satellites. The main crops were wheat, corn, sunflower and grassland. For a more extensive description see Baret [2]. In this study, we focus on winter wheat. In total, five fields of winter wheat were included in the experiment (with id numbers 101, 120, 208, 210 and 300).

\subsection{Field measurements}

During the Alpilles experiment, canopy measurements were carried out at the wheat fields with time intervals varying between 8 and 10 days (fields: 101, 120) and 18 and 20 days $(208,210,300)$. At each date, 6 samples of $0.50 \mathrm{~m}$ by 3 rows (between 0.21 and $0.26 \mathrm{~m}^{2}$ ) were used to determine the total aboveground fresh and dry biomass and its decomposition between organs (green and yellow leaves, stems, and ears). A subsample of 6 plants was collected in the immediate vicinity of each of these 6 samples. The total leaf surface of the $6 \times 6$ plants was measured with a planimeter, as well as the fresh and dry biomass. The LAI was then determined by extrapolating the leaf surfaces obtained on the 6 subsamples to the 6 samples, using the ratio of the biomass of the samples and the subsamples. Additional information was also described such as the crop calendar, canopy height, row direction and stand density. Final yield figures were obtained too. All this information is available in the ReSeDA database (www.avignon.inra.fr/reseda).

\subsection{Remote sensing data}

For this study six SPOT images were acquired. Four of them were within the 1997 growing period of the wheat crops (namely February 1st, March 25th, May 2nd and July 7th). The SPOT images were first radiometrically corrected. Atmospheric correction using the $6 \mathrm{~S}$ software [17] was applied. The aerosol model was based on actual atmospheric optical thickness measurements during satellite overpass, using a sun photometer installed at the test site. Direct and diffuse fluxes were calculated and multiple interactions between target and atmosphere were included. Adjacency effects were neglected because pixel size was small relative to field size and pixels close to field boundaries were not included in data extraction. Actual viewing and solar angles were used in the model. The viewing angle was within $3^{\circ}$ from nadir for all cases. The solar zenith angle during recording was $63^{\circ}$

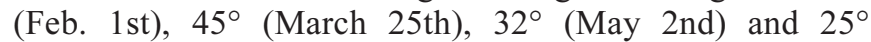
(July 7 th), respectively. Isotropic reflectance by the wheat crop was assumed $[6,7]$. Subsequently, the images were geometrically corrected to the Lambert II extended projection system. Finally, the mean and standard deviation of the reflectances in the three SPOT spectral bands was derived for the relevant fields for all observation dates (present in the ReSeDA database). 


\section{RESULTS AND DISCUSSION}

\subsection{Destructive LAI measurement}

The LAI was obtained in the field from destructive biomass measurements and the specific leaf area. Figure 1 shows the results for the wheat fields (plots) studied. Wheat field 101 exhibited a low LAI during the whole growing season, with a maximum LAI of about one. The other fields obtained LAI values above two. Field 300 shows striking results, because the LAI dropped early in the season in comparison with the other fields. Figure 1 also illustrates that measurement inaccuracy may disturb the interpretation and further use of these data. An example is the deviating value for field 120 at day 134. In order to smooth the LAI curves and to make interpolation between measurement dates easier, curve fitting was applied. Continuous logistic functions [15], including a vegetative period and a senescence period, were fitted to the green LAI measurements:

$$
\begin{gathered}
\mathrm{LAI}(\mathrm{t})=\mathrm{M} \times(\operatorname{GRO}(\mathrm{t})-\mathrm{SEN}(\mathrm{t})) \\
\text { with: } \operatorname{GRO}(\mathrm{t})=1 /\left(1+\exp \left(-\mathrm{a}\left(\mathrm{t}-\mathrm{t}_{\mathrm{i}}\right)\right)\right) \\
\mathrm{SEN}(\mathrm{t})=1 /\left(1+\exp \left(-\mathrm{b}\left(\mathrm{t}-\mathrm{t}_{\mathrm{s}}\right)\right)\right)
\end{gathered}
$$

where $t$ is the day of the year in 1997 and $M, a, t_{i}, b$ and $t_{s}$ are parameters estimated by non-linear fitting, minimizing the residual sum of squares.

Table I provides the results of the curve fitting. In addition to the obtained values of the fitted parameters for the various wheat fields, the residual root mean square errors (rmse) in $\mathrm{m}^{2} / \mathrm{m}^{2}$ units are given. For field 208 no curve was fitted because measurements at the beginning of the growing season were missing. Figure 2 shows the fitted curves. This figure again shows the low LAI values for field 101 in comparison with the other fields. Also, the early drop in the LAI values for field 300 is evident.

\subsection{Estimating LAI from remote sensing}

First, the WDVI values for the five wheat fields studied were calculated according to equation (1). The NIR and red reflectances were field averages obtained from the calibrated

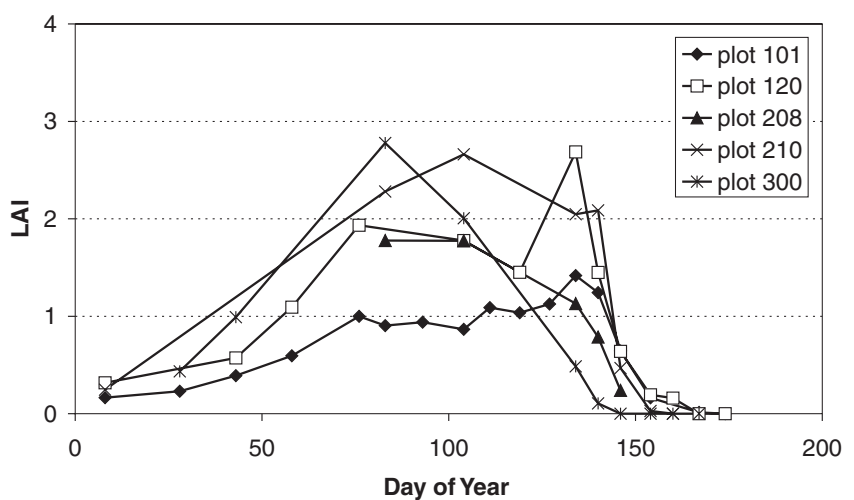

Figure 1. LAI field measurements for wheat fields in 1997 (day of year) at the Alpilles test site.
Table I. Results for a logistic curve fitting to LAI measurements of wheat fields at the Alpilles experiment.

\begin{tabular}{lcccccc}
\hline Field-id & $\mathrm{M}$ & $\mathrm{a}$ & $\mathrm{t}_{\mathrm{i}}$ & $\mathrm{b}$ & $\mathrm{t}_{\mathrm{s}}$ & $\mathrm{rmse}$ \\
\hline 101 & 1.201 & 0.06426 & 52.7 & 0.4456 & 147.4 & 0.17 \\
120 & 1.995 & 0.08193 & 53.4 & 0.3872 & 143.9 & 0.28 \\
210 & 2.274 & 0.06485 & 43.4 & 0.4212 & 144.7 & 0.13 \\
300 & 6.948 & 0.04504 & 86.0 & 0.0695 & 110.2 & 0.05 \\
\hline
\end{tabular}

SPOT images. In addition, the slope of the soil line (C) had to be calculated for the test region. Bare fields during the SPOT recordings of 1997 and harvested wheat fields, visible on the SPOT image of August 30th, 1997, provided NIR and red reflectances, derived from the images, for bare soil. The estimate of $\mathrm{C}$ yielded a value of 1.26. Using this estimate, the WDVI was calculated from the four SPOT images within the growing season of wheat. Figure 3 shows small WDVI values for wheat field 101 in comparison with the other fields. This coincides with the small LAI values found from the field measurements. The order in maximum WDVI matched the order in maximum LAI as illustrated in Figure 2. Figure 3

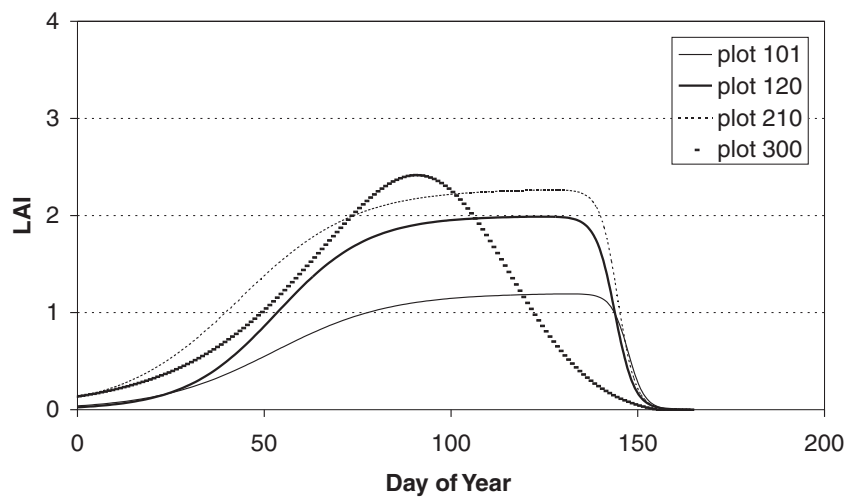

Figure 2. Logistic curves fitted to the LAI field measurements for wheat fields in 1997 at the Alpilles test site.

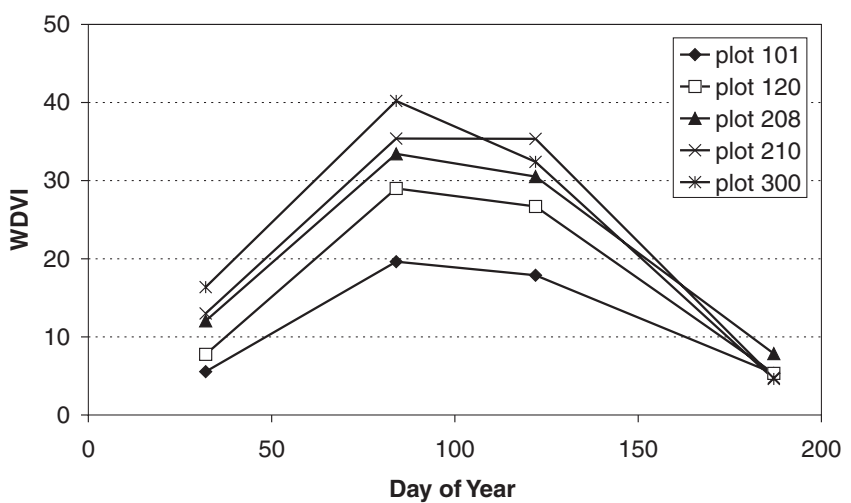

Figure 3. WDVI estimates for wheat fields derived from the 1997 SPOT images at the Alpilles test site. 
even suggests the early drop in WDVI values for field 300, as was also found in Figures 1 and 2 in terms of LAI.

Subsequently, the parameter estimates obtained from Clevers [7] were used for deriving estimated LAI values from these WDVI values according to equation (2). A subdivision into the vegetative growth stage (first two SPOT dates) and the reproductive growth stage (last two SPOT dates) was made. At the vegetative stage, Clevers found a value of 0.252 for $\alpha$ and a value of 68.6 for $\mathrm{WDVI}_{\infty}$ At the reproductive stage, he found a value of 0.530 for $\alpha$ and a value of 57.9 for WDVI $_{\infty}$ Figure 4 illustrates the estimated LAI based on the SPOT data. From this figure similar conclusions to those for the WDVI curves can be drawn.

Finally, the LAI estimates for wheat, derived from the SPOT data, were compared with the destructive field measurements of LAI. The fitted logistic growth curves (Fig. 2) were used to obtain interpolated values for the SPOT observation dates. Results of the comparison between SPOT-derived LAI estimates and field measurements are illustrated in Figure 5. Since the SPOT observation of July 7 th occurred just around the harvesting dates of the wheat fields, this date

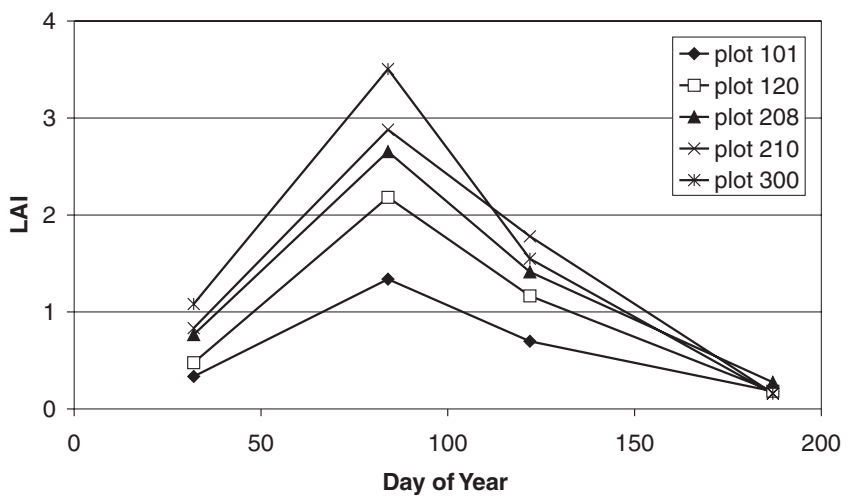

Figure 4. Estimated LAI values derived from SPOT images in 1997 for wheat fields at the Alpilles test site.

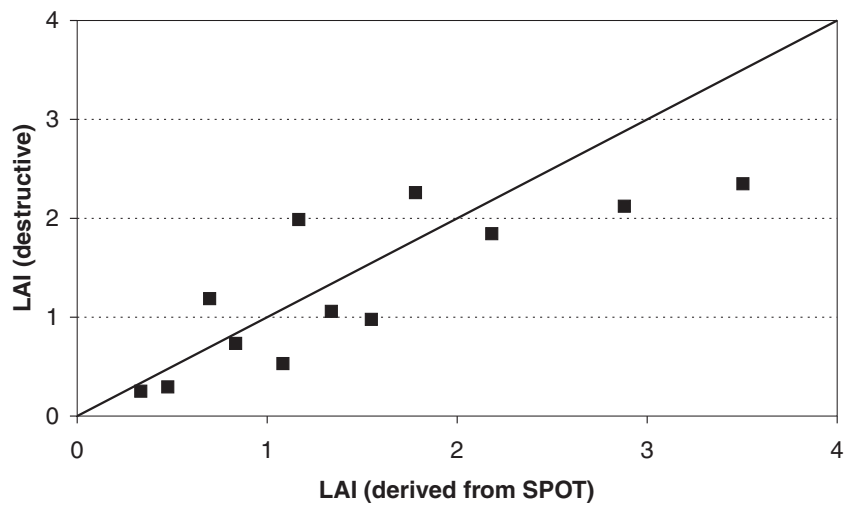

Figure 5. Comparison between the LAI derived from SPOT data and field measurement of LAI for wheat fields in 1997 at the Alpilles test site. was not included in the comparison with field measurements. Also, field 208 was omitted because not enough field measurements were obtained to do a proper curve fitting. A good correspondence between the field measurements and the LAI estimates from SPOT data was obtained $(\mathrm{rmse}=0.57)$. This result suggests that the methods and parameters derived for wheat in the Netherlands can be applied to wheat grown in Southern France. Moreover, the methodology developed for ground-based and airborne remote sensing data can also be applied using spaceborne measurements.

\subsection{Calibrating a crop growth model}

Jongschaap [12] calibrated and validated the ROTASK crop growth model for wheat with data from the 1996, 1997 and 1998 growing seasons obtained for the Alpilles test site. First, this included the definition of soil profiles representing the soils of the test area. Secondly, the temperature sums for the determination of development stages of the wheat crop and the dry matter partitioning at each development stage were adjusted. Finally, the root growth and water uptake potentials by the root system were adjusted. As a result, one may expect to have a well-calibrated wheat growth model for this region at one's disposal. Using this calibrated model, growth of the wheat fields studied (1997 growing season) was simulated using actual meteorological data and, for each field, the actual sowing, emergence and harvest dates. Figures 6 and 7 illustrate the simulation ('SIM') results of LAI for the fields 101 and 120, respectively, together with the field measurements. As stated before, these fields were most intensively sampled in the field. Both figures show that the simulated LAIs were high in comparison with the field measurements. Also, the LAI values in reality rose earlier in the season than those simulated. Apparently, the dry growing conditions in 1997 caused an overestimation by the simulation model.

Subsequently, actual remote sensing information per field was used in two ways to calibrate the crop growth model. In the first method, the simulated LAI was reset to the actual value estimated from the SPOT images at the SPOT observation dates. This means three moments of resetting, namely at days 32, 84 and 122. After the reset day, ROTASK again simulates the growth and development of the crop from day to day until the next reset. The results are also illustrated in Figures 6 and 7 ('SIM+RESET'). The results show that the first reset at day 32 (February 1st) increased the LAI value, so that the initial growth was better simulated than without the reset. For winter wheat actual information about growth after the winter period appeared to be very important. The reset dates in the middle of the growing season (day 84 and 122) pulled the simulated LAIs back to approximately the level of the field measurements. The simulation model again simulated values that were too high.

In the second calibration method, the crop growth model simulated growth and development until the first SPOT observation date (and eventually after the last one). After that the LAI was estimated from day to day by interpolating the estimated LAI values between the SPOT observation dates. 


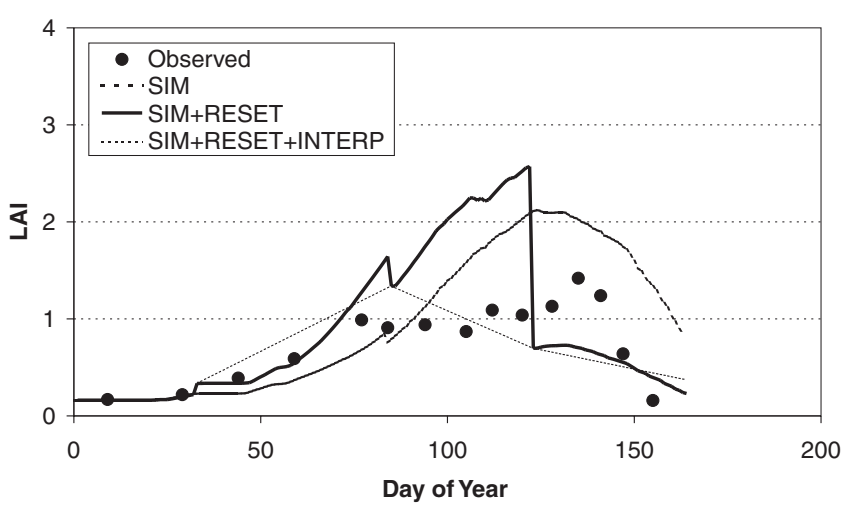

Figure 6. The 3 simulation methods applied for LAI simulation as a function of the day of year in 1997 on winter wheat field 101 at the Alpilles test site. SIM means only use is made of the simulation model; SIM+RESET means that remote sensing data are used for a reset of simulated LAIs; SIM+RESET+INTERP means that interpolated LAI estimates from remote sensing data are "forcing" the simulation model.

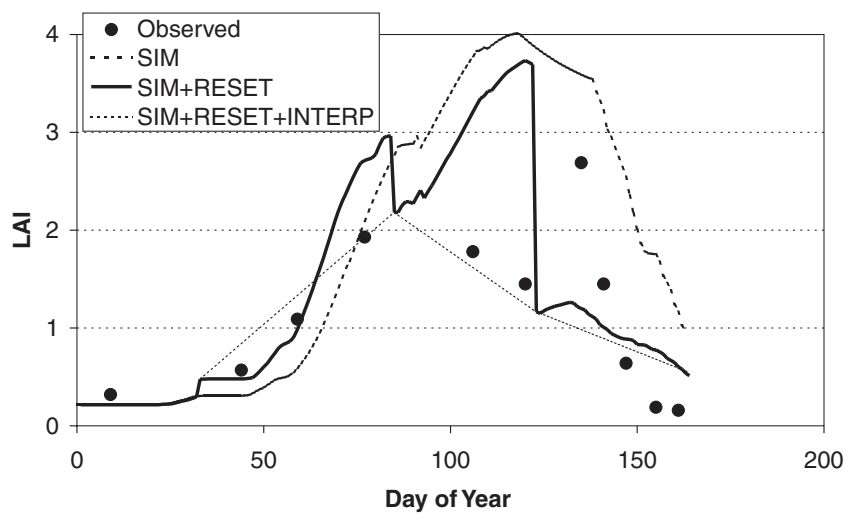

Figure 7. The 3 simulation methods applied for LAI simulation as a function of the day of year in 1997 on winter wheat field 120 at the Alpilles test site. For further explanation see Figure 6.

These values were then "forced" on the simulation model. As a result the model was mainly used for simulating crop development and the partitioning of dry matter over the various organs. These results are also illustrated in Figures 6 and 7 ('SIM+RESET+INTERP'). Clearly a better fit to the observations was obtained with this latter method. As can be seen from Figures 6 and 7, the error in estimating LAI from SPOT data was introduced directly into the crop model. Nevertheless, it is clear that LAI estimates became more accurate, compared with the observed values.

Table II provides a summary of the obtained results for the comparison of LAI values against the field observations for all fields studied. As the results in Table II indicate, the introduction of remote sensing data increased the accuracy of the LAI estimates. When testing the average decrease in rmse by using remote sensing information for resetting the simulation
Table II. Root mean square errors of LAI $\left(\mathrm{m}^{2} \cdot \mathrm{m}^{-2}\right)$ for the 3 simulation methods. Numbers in brackets point to the number of observations.

\begin{tabular}{llll}
\hline Field-id & Simulation & $\begin{array}{l}\text { Simulation } \\
+ \text { reset }\end{array}$ & $\begin{array}{l}\text { Simulation, } \\
\text { reset }+ \\
\text { interpolation }\end{array}$ \\
\hline 101 & $0.685(16)$ & $0.704(16)$ & $0.369(16)$ \\
120 & $1.405(11)$ & $1.003(11)$ & $0.601(11)$ \\
208 & $0.936(7)$ & $0.564(7)$ & $0.481(7)$ \\
210 & $0.616(7)$ & $0.485(7)$ & $0.633(7)$ \\
300 & $1.104(7)$ & $0.635(7)$ & $0.686(7)$ \\
\hline Average & $0.984(48)$ & $0.731(48)$ & $0.537(48)$ \\
\hline
\end{tabular}

Table III. Root mean square errors of grain yield estimates $\left(\mathrm{t} \cdot \mathrm{ha}^{-1}\right)$ for the 3 simulation methods (observations throughout the growing season) in 1997. Numbers in brackets point to the number of observations. n.a. means "not available": for field 300 the rate of senescence was so high that LAI was zero well before harvest time and as a result the modeling using the forcing stopped.

\begin{tabular}{llll}
\hline Field-id & Simulation & $\begin{array}{l}\text { Simulation } \\
+ \text { reset }\end{array}$ & $\begin{array}{l}\text { Simulation, } \\
\text { reset }+ \\
\text { interpolation }\end{array}$ \\
\hline 101 & $2.60(8)$ & $0.77(8)$ & $0.96(8)$ \\
120 & $1.46(8)$ & $0.56(8)$ & $0.96(8)$ \\
208 & $0.89(6)$ & $1.66(6)$ & $2.71(6)$ \\
210 & $1.02(2)$ & $0.89(2)$ & $2.63(2)$ \\
300 & $2.01(5)$ & $1.14(5)$ & n.a. \\
Average & $1.84(29)$ & $1.05(29)$ & $1.74(24)$ \\
\hline
\end{tabular}

model $(\mathrm{rmse}=0.731)$ in comparison with just using the simulation model $(\mathrm{rmse}=0.984)$, it proved to be significant at the $95 \%$ confidence level. When using remote sensing information for "forcing" continuously on the simulation model (rmse $=0.537)$ the additional improvement was also significant at the $95 \%$ confidence level.

Table III shows that the accuracy of the yield component of the biomass simulation (being the grain yield throughout the growing season) did not increase in the same way as that of the LAI. The reset using remote sensing information yielded a significant improvement, but the "interpolation" reduced the accuracy again significantly. This may be due to the fact that leaf area values are specifically well estimated at the beginning of the growing season, while for yield formation, the values at the grain filling period are more important. For the "forcing" procedure, insufficient remote sensing measurements throughout the growing season were obtained to get accurate estimates of grain yield. As an example, Figure 8 illustrates the results of the three simulation procedures in terms of grain yield for field 120 . The relatively high values of the rmse were due to deviations in the first phase after flowering. 


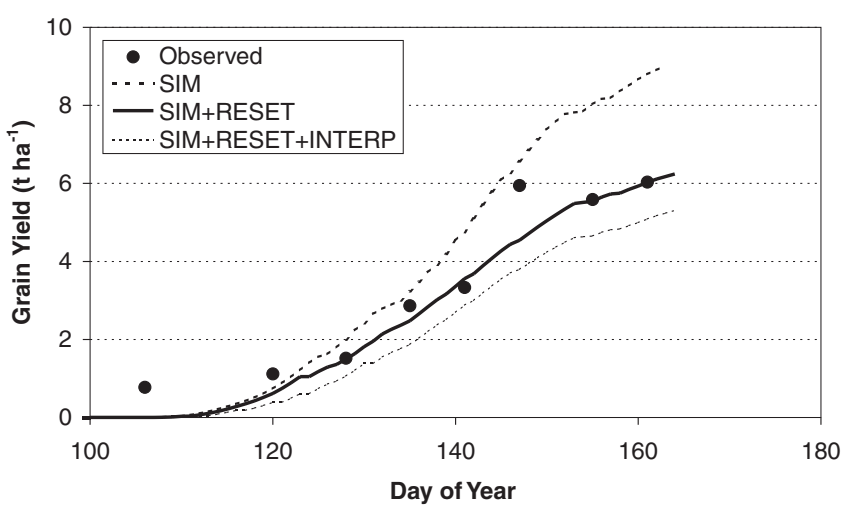

Figure 8. The 3 simulation methods applied for grain yield simulation as a function of the day of year in 1997 on winter wheat field 120 at the Alpilles test site. For further explanation see Figure 6.

Table IV. Deviations in final yield $\left(\mathrm{t} \cdot \mathrm{ha}^{-1}\right)$ for the 5 winter wheat fields in 1997 (Simulated - Observed). The average presents the average absolute deviation.

\begin{tabular}{llll}
\hline Field-id & Simulation & $\begin{array}{l}\text { Simulation } \\
+ \text { reset }\end{array}$ & $\begin{array}{l}\text { Simulation, } \\
\text { reset }+ \\
\text { interpolation }\end{array}$ \\
\hline 101 & 3.09 & -0.44 & -1.95 \\
120 & 2.76 & 0.07 & -0.86 \\
208 & 0.85 & -0.51 & -1.66 \\
210 & 0.94 & -0.85 & -2.66 \\
300 & 3.45 & 0.75 & n.a. \\
Average & 2.22 & 0.52 & 1.78 \\
\hline
\end{tabular}

Finally, Table IV provides the deviations $\left(\mathrm{t} \cdot \mathrm{ha}^{-1}\right)$ in final yield simulations for the three methods from the actual yield figures. The results show that the reset using remote sensing information yielded a significant improvement in final yield estimation. Again, the "interpolation" yielded no significant improvement. In this respect, it is important to realize that the growth model used was initially calibrated on field data from the study area, including the year of the study, and the actual sowing and emergence dates were included. Moreover, for yield formation, a good calibration of the growth model at the grain filling period is most important. This is the last part of the growing season, and we actually had only one SPOT observation date within the grain filling period, which started at about day 100 .

\section{CONCLUSION}

In this study our focus was on testing the semi-empirical approach for estimating LAI of a wheat crop, which was developed for the Netherlands using ground-based and airborne data, on wheat crops grown in Southern France. Moreover, we tested the use of SPOT data for this purpose.

The results show that the semi-empirical CLAIR model can be used for estimating LAI of wheat fields in Southern France. The parameters derived for cereals in the Netherlands can be applied in Southern France. Moreover, the relationships and methods derived from ground-based and airborne observations can be applied to spaceborne measurements. This indicates that this approach may have a broad applicability and that parameter estimates are not site-specific. In this study the root-mean-square error of the LAI estimates decreased from 0.98 to 0.54 (Tab. II). In this respect, it must also be noted that it was difficult to get accurate LAI estimates from field measurements, which are representing a whole field (cf. Fig. 1). So, the final rmse is expected to be caused in large part by the field measurements.

Often the lack of specific field data hampers the good calibration of mechanistic simulation models like Rotask 1.5. Remote sensing has proven to offer a valuable tool for run-time calibration, leading to better estimates of LAI and grain yield in situations where only average values for model input parameters are available. This means that remote sensing data can improve regional estimates of crop production, which is important for policy, logistics and trade activities [16]. In particular, the estimation and even the prediction of crop yields per field can be improved with satellite imagery. In this study, we could only improve the yield estimates by using satellite imagery to reset the modeling at the observation dates. Continuous "forcing" of interpolated LAI values on the modeling did not improve the yield estimates significantly. This will partly be caused by the fact that actual sowing and emergence dates per field were used in the growth simulations. In practice, this information will not be available for each individual field. Optical remote sensing data may provide a significant improvement in yield estimations when this information concerning sowing dates is not available [9]. Moreover, for accurate yield estimates, information at the grain filling period will be particularly important.

By using high-resolution satellite imagery, one can even get detailed information about crop growth within fields. By applying the same methodology at the pixel level, one can obtain differences in LAI within the individual fields. This can illustrate that yields vary across a field too, which is something farmers are quite aware of. However, by linking this information to a database and to control systems on the farmer's equipment (including global positioning systems), the way is opened to help farmers manage their crops in an efficient and site-specific way. The role of simulation models can be to evaluate theoretically how to optimize management practices in order to get a maximum profit and/or a minimum environmental impact. This is known as precision farming. The derivation of crop-specific information from satellite imagery, as described in this paper, is a key item in this application field. The results of this study have shown that this may be a fruitful way to use it, yielding generally applicable algorithms and parameters. The testing of this must be extended in future to other crops and other regions. 
Acknowledgements: The Alpilles-ReSeDA project was funded by the EEC-DG XII (contract ENV4-CT96-0326 - PL952071) and the French Programme National de Télédétection Spatiale and Programme de Recherches en Hydrologie. The IRSA-MARS project provided access to ground data and SPOT images (Arles segment).

\section{REFERENCES}

[1] Asrar G., Fuchs M., Kanemasu E.T., Hatfield J.L., Estimating absorbed photosynthetic radiation and leaf area index from spectral reflectance in wheat, Agron. J. 76 (1984) 300-306.

[2] Baret F., ReSeDA: Assimilation of multisensor \& multitemporal remote sensing data to monitor soil and vegetation functioning, Final Report EC project ENV4CT960326, INRA, France, 2000, 59 p.

[3] Bouman B.A.M., Linking X-band radar backscattering and optical reflectance with crop growth models, Ph.D. Thesis, Wageningen Agricultural University, Wageningen, the Netherlands, 1991, 169 p.

[4] Bouman B.A.M., Van Kasteren H.W.J., Uenk D., Standard relations to estimate ground cover and LAI of agricultural crops from reflectance measurements, Eur. J. Agron. 4 (1992) 249-262.

[5] Clevers J.G.P.W., The derivation of a simplified reflectance model for the estimation of Leaf Area Index, Remote Sens. Environ. 25 (1988) 53-69.

[6] Clevers J.G.P.W., The application of a weighted infrared-red vegetation index for estimating Leaf Area Index by correcting for soil moisture, Remote Sens. Environ. 29 (1989) 25-37.

[7] Clevers J.G.P.W., Application of the WDVI in estimating LAI at the generative stage of barley, ISPRS J. Photogramm. Remote Sens. 46 (1991) $37-47$.

[8] Clevers J.G.P.W., Van Leeuwen H.J.C., Combined use of optical and microwave remote sensing data for crop growth monitoring, Remote Sens. Environ. 56 (1996) 42-51.
[9] Clevers J.G.P.W., Büker C., Van Leeuwen H.J.C., Bouman B.A.M., A framework for monitoring crop growth by combining directional and spectral remote sensing information, Remote Sens. Environ. 50 (1994) 161-170.

[10] Delécolle R., Maas S.J., Guérif M., Baret F., Remote sensing and crop production models: present trends, ISPRS J. Photogramm. Remote Sens. 47 (1992) 145-161.

[11] Jongschaap R.E.E., ROTASK 1.0: a dynamic simulation model for continuous cropping and tillage systems, Reference manual. Haren DLO Research Institute for Agrobiology and Soil Fertility, AB-DLO Report 70, the Netherlands, 1996, $41 \mathrm{p}$.

[12] Jongschaap R.E.E., Calibration and validation of ROTASK 1.5 simulation model on field data of the ReSeDA project in Southern France, With special reference to winter wheat, Plant Research International, Report (XX). Wageningen, the Netherlands, 2002, (in press).

[13] Maas S.J., Use of remotely sensed information in agricultural crop growth models, Ecol. Modell. 41 (1988) 247-268.

[14] Prévot L., Baret F., Olioso A., Wigneron J.P., Clevers J.G.P.W., Jongschaap R.E.E., Assimilation of multi-temporal remote sensing data to monitor vegetation and soil, the Alpilles-ReSeDA project, Proc. IGARSS '98 Symposium, July 1998, Seattle, WA, USA, 1998, 3 p.

[15] Schnute J., A versatile growth model with statistically stable parameters, Can. J. Fish. Aquat. Sci. 38 (1981) 1128-1140.

[16] Van Leeuwen H.J.C., Schouten H., Jongschaap R.E.E., King C., Predicting wheat production at the regional scale by the assimilation of remote sensing data with the crop growth simulation model ROTASK v1.5, Proceedings of the 25th EGS General Assembly, Nice, France, 25-29 April 2000, www.avignon.inra.fr/reseda/base/documents/reseda-report/RES-225.pdf (verified on June 14, 2002).

[17] Vermote E.F., Tanré D., Deuzé J.L., Herman M., Morcrette J.J., Second simulation of the satellite signal in the solar spectrum, 6S: An overview, IEEE Trans. Geosci. Remote Sens. 35 (1997) 675-686. 